\title{
Knowledge Tree:
}

\section{putting discourse into computer-based learning :}

\author{
T. J. Brailsford, P. M. C. Davies, S. C. Scarborough and W. J. Trewhella \\ Department of Life Science, University of Nottingham
}

\begin{abstract}
Most CBL materials currently in use model only the declarative aspects of the learning process. If such courseware is used without careful planning, this can be dangerous because one of the most fundamental aspects of education is the dialogue that occurs between teachers and the students. Traditionally, this has taken place in informal discussions as well as in formal small-group learning sessions such as the conventional tutorial. However, as the student-staff ratio increases, so does the opportunity for this type of personal dialogue decrease. Modern networking technology offers a huge potential to add discourse to $C B L$, but there are many pedagogical problems involved with the intrinsically ephemeral and anarchic nature both of the Internet and of most conferencing or bulletinboard systems. In this paper we describe a software system called Knowledge Tree (KT) which we have developed to address some of these issues. KT combines a hierarchical concept-oriented database functionality with that of a Usenet-style bulletin board Using this, a knowledge garden may be developed for any subject area. These each contain a hypermedia database of frequently asked questions, together with answers provided by subject experts. There is provision for inter-student discussions of problems and issues. Then students ask new questions these are automatically emailed to a relevant subject expert (determined by a subject-specific concept thesaurus). The answer is then placed in the database which eventually grows to become a valuable teaching resource. $K T$ is disciplineindependent as the concept thesaurus can be changed to encapsulate any domain of knowledge. We have used it in support of conventional lecture courses, as an important component of a multimedia course, and for general IT support. These examples illustrate the role that this system can play both in basic information provision, and in facilitating the discussion of deep issues.
\end{abstract}

\section{Introduction}

\section{The learning process}

One of the most fundamental aspects of education is the dialogue that occurs between teachers and the students. Laurillard (1993) has discussed this in depth, and has concluded that any teaching strategy should make provision for a dialogue which reveals the conceptions of both the teacher and the student. This allows the teacher to analyse the students' understanding, and to use this information to form the basis of subsequent dialogue. 
Traditionally this process has taken place in informal discussions, as well as in formal small-group learning sessions such as the (old-fashioned) tutorial. A real problem that is currently facing education is that as the student-staff ratio increases, so the opportunity for personal dialogue decreases. In many university departments, tutorials have much less pre-eminence than they once did because they are often not perceived as being a costeffective form of teaching in comparison with declarative methods such as lecturing.

\section{IT-based teaching strategies}

Computer-based learning (CBL) is currently being widely promoted as the saviour of teaching quality in the face of diminishing resources. Although it is true that CBL has this potential, there is a real danger that if IT-based educational strategies are not implemented very carefully they could damage the learning process. The majority of courseware currently available is primarily declarative, embodying the 'show and tell' learning model. When this is used as part of a carefully designed teaching strategy, such material can be extremely valuable, but it must be remembered that it models only one type of teaching.

The learning process can be viewed as a perpetual cycle of three phases, each of which can potentially be reproduced in courseware (Mayes, 1993; Mayes and Neilson, 1995). This starts with the initial conceptualization of the subject material from declarative sources (for example, lectures or books). There are then phases of construction (for example, essay writing or problem solving) and dialogue. Students who fail to perform adequately in the construction or dialogue phases can be given the assistance they require to improve their conceptualization.

Most pieces of courseware are intended for the primary exposition of subject material, and thus tend to be declarative in nature. This is what Mayes and Neilson (1995) have termed primary courseware. Secondary courseware uses the constructionist model of learning, and provides tools and objectives for students to enable them to manipulate resources (i.e. the students effectively become the authors of their own courseware). Tertiary courseware provides distributed learning support, and in CAL it is this which can create the dialogue that is so essential to effective learning.

\section{Collaborative learning}

Barrett (1989) has pointed out that when computers are used in education, the social processes of interaction and collaboration that occur during learning should be modelled in the computer. Collaborative group-learning is a well established educational strategy, which is readily amenable to extension and enhancement by IT (Collis, 1994). In a study of a computer-supported collaborative learning system, Alavi (1994) found that students attained a higher level of skills development and self-reported learning than did their conventionally taught colleagues. An important aspect of this type of collaborative learning is that not only is there an opportunity for dialogue between students and their teachers, but there are also opportunities for discussion amongst peers. A major feature of the JITOL (Just-In-Time Open Learning) project is that peer discussions are used to create a hyperstack of public knowledge (Boder, 1992; Goodyear and Steeples, 1992). The rationale of this is a process that Boder (1992) calls the 'reification of interactions'. This involves new knowledge being acquired by a recursive process of debate which stems from previous knowledge. This newly acquired knowledge is then used as the basis for continuing debate. 
The recent massive expansion of global networking technology has provided a number of new opportunities for learning through dialogue. Automated email distribution lists and Usenet news provide a means of distributed electronic debate. There are, however, problems with using such systems for teaching. Email lists are an effective means for distributing information to a large audience, but they tend to be a clumsy forum for debates. If an individual subscribes to a significant number of lists, he or she will be continually bombarded with parts of discussions on a variety of subjects. Usenet is rather better on this score, but its intrinsically anarchic and ephemeral nature inevitably pose serious problems if it is used for teaching.

\section{The Answer Garden approach to learning}

A number of systems, of varying levels of sophistication, have been developed that address some of these problems. The most interesting and innovative of these has been the Answer Garden (Ackerman and Malone, 1990; Ackerman, 1994).

Answer Garden was not originally designed for use in education, but rather for the distribution of information from an organization's 'memory'. This 'organizational memory' is that diffuse pool of authoritative knowledge present in an organization but not in any individual. Answer Garden was designed to provide a means to tap this pool, and it was envisaged that this would be used for purposes such as technical support or customer hot-lines. In such environments there is a continual stream of questions, most of which recur frequently, but there are always some that are novel. Answer Garden presents users with a branching network of diagnostic questions about their problem. If there is an appropriate answer in the database, this will be found; but if there is no such answer, an email will automatically be sent to a relevant subject expert. Both the question and the answer are eventually incorporated into the database which thus grows 'organically'.

In our view, this basic approach to knowledge dissemination is also highly applicable to education. However, there are a number of ways in which the original Answer Garden is not ideal for educational use, the most important of which is that each user is fundamentally isolated. He or she can see questions that others have asked in the past, but has no knowledge of who else is currently using the system or what they are discussing. If used for teaching, Answer Garden would provide a student-teacher dialogue, but no peer-peer interaction.

In order to address some of these issues we have developed a software system called Knowledge Tree (KT) inspired by the Answer Garden concept but extended in a number of important ways. We have been using this system in undergraduate teaching since early 1994.

\section{Knowledge Tree: a collaborative learning tool for networks}

The KT software combines a bulletin board (BB) functionality with a hierarchical concept-oriented database to provide a structured environment to host and archive discussions at both a student-student and student-teacher level. Using KT, a knowledge garden may be developed for any. subject area, and these each contain a database of frequently asked questions together with live discussions of problems and issues. 


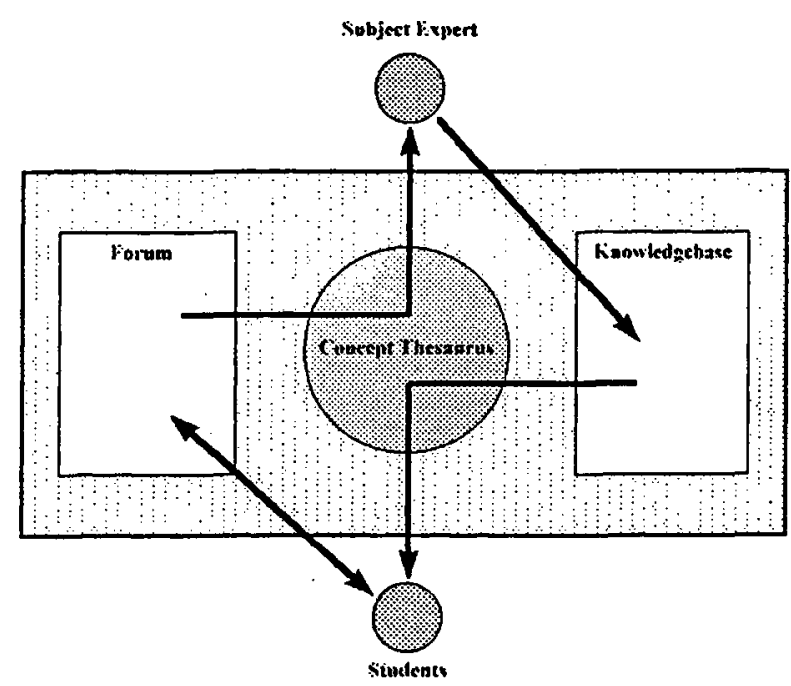

Figure 1: The Knowledge Tree system model

The system model is shown in Figure 1. KT is divided in to two distinct but related components called the Forum and the Knowledgebase. The Forum contains primarily student-student interaction and is essentially a threaded BB where students can ask questions and participate in ongoing debates. New questions asked in the Forum are automatically emailed to relevant subject experts, and together with the answers they are archived in the Knowledgebase, which is effectively a subject-specific hypermedia database.

\section{Epistemology}

Each garden has its own subject-specific thesaurus consisting of a hierarchy of concepts that is displayed as a folding 'outline'. In the Forum, students use this to attach a concept to their question, and in the Knowledgebase it forms a browser used for navigation. The thesaurus uses a system of upward inheritance to provide a powerful means of structuring any subject domain. For example, using the simple thesaurus shown in Figure 2, any

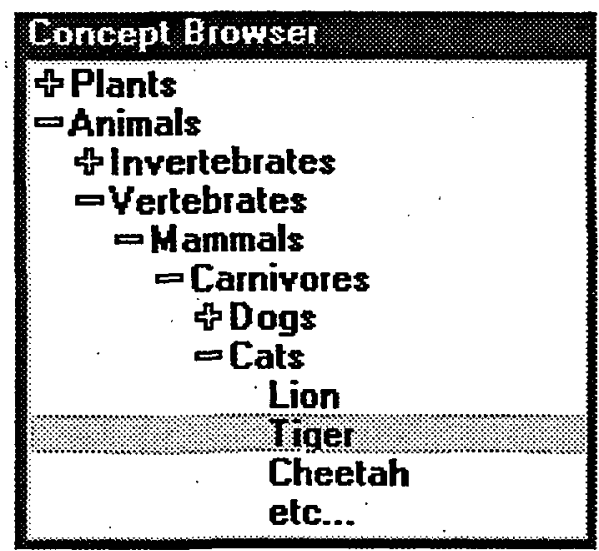

Figure 2: An example of a simple concept thesauns to illustrate the use of inheritance 
question with the concept of 'tiger' attached to it would be found under Carnivores or Cat, but not under Dog.

\section{Dialogue in the garden}

In the Forum, students can see the questions their peers have asked, and can comment on them or answer them (see Figure 3). This results in discussion threads similar to those found in Usenet or most BB systems. Articles in a thread are not automatically deleted, but instead the entire thread is removed once it is obsolete. This avoids the problem of decapitated threads that bedevils systems such as Usenet: frequently, users find they can read part of a thread, but not the original posting. This can lead to the vague ambling from one subject to another that is so common in news groups; it can be entertaining and sometimes informative, but it is not ideal for the type of debate that should be encouraged in education. While reading a thread in the Forum, the students may press a button and jump to the appropriate Knowledgebase article (see Figure 4). KT thus supports dialogue both between peers, and between students and their teachers. The Forum provides an area of dynamic debate, but Knowledgebase articles are permanent. Thus the garden grows with time, eventually to become a valuable resource.

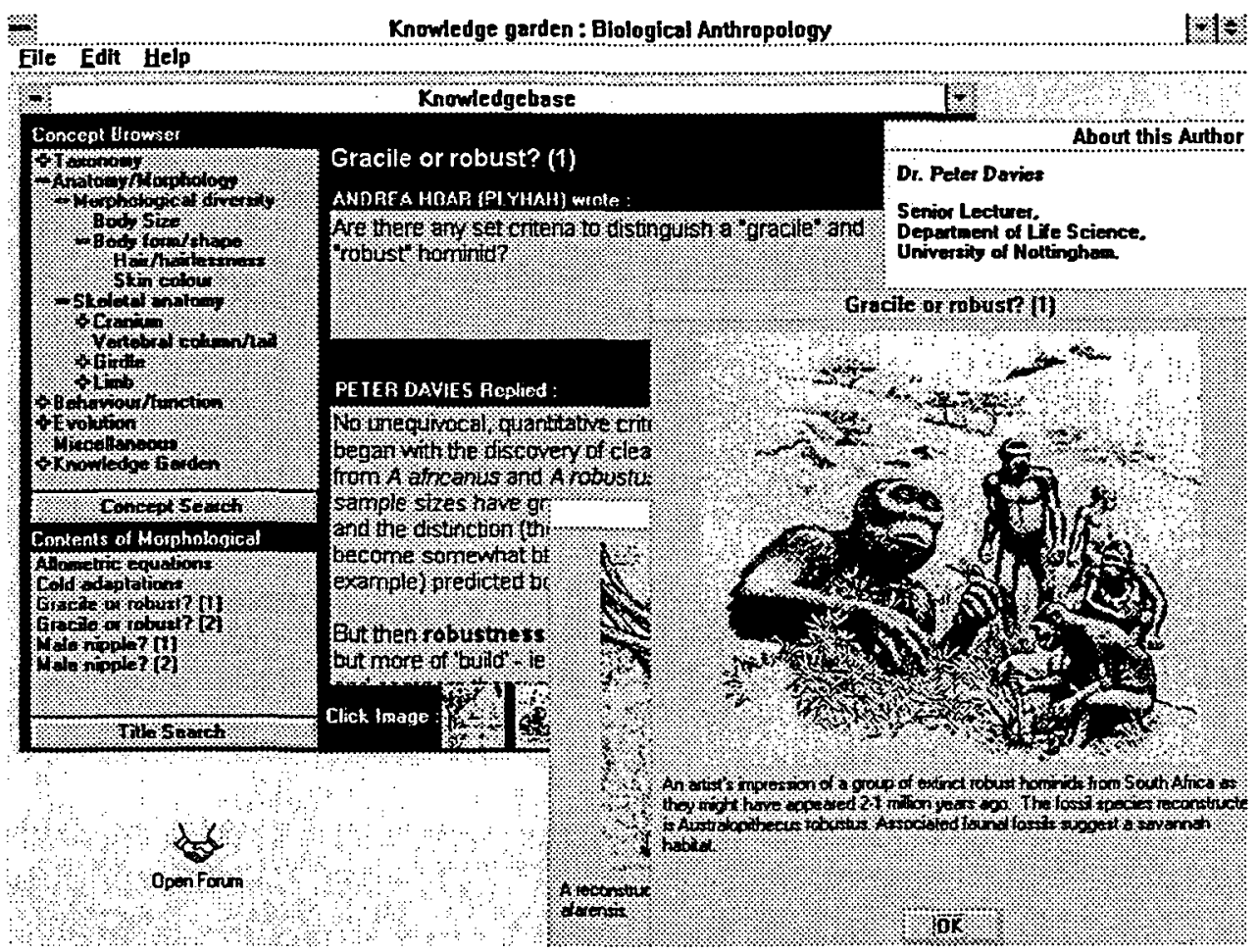

Figure 3: Part of the Knowledgebase from a Biological Anthropology knowledge garden

\section{The Knowledge Tree in use}

We have used $\mathrm{KT}$ in quite a number of different applications for three cohorts of students. It provides ancillary support for two conventional lecture courses, and forms a 


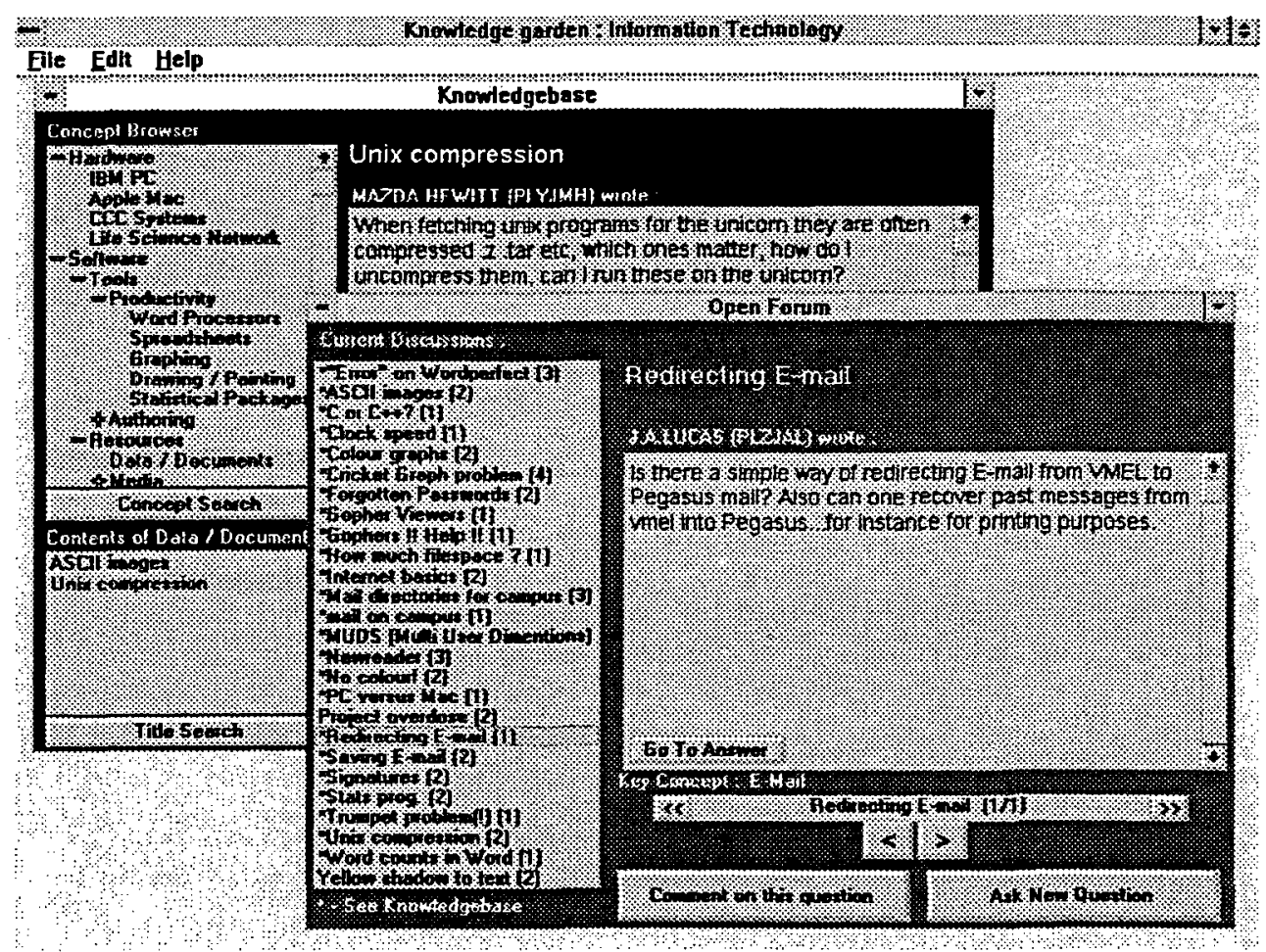

Figure 4: Part of the Fonum from an Information Technology knowledge garden

major component of a module based entirely around CBL. In addition, it is used to support general IT queries in our department. Some long threads have been developed about quite deep issues, and some of the student contributions have been of extremely high quality (in a number of cases we have transferred student answers directly to the Knowledgebase).

One of the main aims of KT is to lighten the burden of responding to student problems, as queries automatically go to the most appropriate available expert. Once a query is answered, this is publicly available until it is no longer appropriate. A good answer should promote reflection and further study rather than provide a package of selfcontained information. In the case of universities, the experts are likely to be academic staff, although this need not be the case. It would be quite feasible to make use of graduate students or teaching assistants to provide answers. There are also potentially many more ways of using KT than we have yet tried. The effort that some students have put into writing articles in the Forum has convinced us that the system has potential as a constructionist tool as well as a learning-support tool. It would be an interesting experiment to run a student-administered garden, where groups of students are allocated a subject domain for which they have to research and create their 'official' answer. It might even be possible for students to create their own gardens from scratch for each other, as building a good thesaurus requires quite a deep understanding of the subject material. Another possibility would be for teachers to ask questions in the Forum to seed 
student debate. KT can also be used on various different scales. On a large scale it can provide support for an entire course and cover many different topics. It is equally usable on a small scale, and would provide an interesting alternative to essay-writing in an electronic equivalent of a tutorial group.

\section{Integrated courseware and the future of CAL}

We have found that KT can provide useful support for conventional teaching methods, and can be a valuable addition to conventional declarative CBL in that it can offer the staff feedback and peer debate that CBL usually lacks. The real potential of this approach to learning will only be realized, however, with fully distributed systems. So far, KT has been used only to support collaborative learning on local-area networks. In the near future, we hope to run KT across wide-area networks, and this opens the interesting possibility of inter-institutional collaboration to provide distributed learning support. Thus instead of a garden being tied to a single course in a single institution, it could be used to support similar courses running concurrently in several different institutions. Students would thus be able to participate in debates with students in other institutions, and the subject experts would be drawn from the staff of all of the participating courses. This would make the most effective use of available staff resources, and provide a dynamic learning experience for the students.

An interesting project that has implemented a distributed approach to the Answer Garden principle is the Answer Web system (Mayes and Neilson, 1995). This is effectively an implementation of the original Answer Garden concept on the World Wide Web. The most important aspect of this is that it can be used in an environment where the World Wide Web is an important element of teaching, and thus it will be seamlessly integrated into other courseware.

We hope eventually to integrate knowledge gardens with more conventional declarative courseware, so that they simply become a tool in a learning-support environment. This raises the interesting possibility of a type of 'living hypertext', where a link in conventional courseware (possibly automatically generated) could take the student to a relevant live discussion in which they could participate. This could, in principle, provide composite courseware that would contain the primary educational material, but would also provide tools allowing students to collaborate with their peers and interact with teachers. Courseware of this type would then be much more capable of fulfilling the entire learning process than most courseware available today, and it could thus be more safely used as a core component of teaching

Lectures and conventional teaching methods are likely to remain important for the foreseeable future, but courseware of the type described above could easily teach the mundane parts of many courses. Lectures could then become the inspirational performance they should be, rather than the mental filling stations they all too often become.

\section{Acknowledgements and further information}

We are most grateful to Don Whittle and Craig Stewart for their help during the development and trials of Knowledge Tree. We should also like to thank Wendy Hall, 
Terry Mayes, Brian Shields and Barry Wood for many useful discussions, Bourne Robinson for programming, and the IBiS team for their support. This work was funded by the ITTI and TLTP. Further information about the Knowledge Tree software can be obtained on the World Wide Web at http://ibis.nott.ac.uk/software/kt.html.

\section{References}

Ackerman, M.S. (1994), Answer Garden: A Tool for Growing Organizational Memory, Ph.D. thesis, Cambridge MA: Massachusetts Institute of Technology.

Ackerman, M.S. and Malone T.W. (1990), 'Answer Garden: a tool for growing organizational memory' in Proceedings of the ACM Conference on Office Information Systems, New York: ACM, 31-9.

Alavi, M. (1994), 'Computer-mediated collaborative learning - an empirical evaluation', MIS Quarterly 18 (2), 159-74.

Barrett, E. (1989), 'Thought and language in a virtual environment' in Barrett, E. (ed.), The Society of Text, Cambridge MA: MIT Press.

Boder, A. (1992), 'The process of knowledge reification in human-human interaction', Journal of Computer Assisted Learning, 8, 177-85.

Collis, B.A. (1994), 'Collaborative learning and CSCW - research perspectives for interworked educational environments', IFIP Transactions, $A$-Computer Science and Technology, 46, 81-104.

Goodyear, P. and Steeples C. (1992), 'IT-based open learning: tasks and tools', Journal of Computer Assisted Learning, 8, 163-76.

Laurillard, D. (1993), Rethinking University Teaching: A Framework for the Effective Use of Educational Technology, London: Routledge.

Mayes, J.T. and Neilson, I. (1995), 'Learning from other people's dialogues - questions about computer-based answers', IFIP Transactions, $A$ - Computer Science and Technology, 61, 31-47.

Mayes, J.T. (1993), 'Commentary: impact of cognitive theory on the practice of courseware authoring', Journal of Computer Assisted Learning, 9, 222-8. 